Article

\title{
Evaluation Indicators Screening Based on Interval Estimation Model--Taking Location of Production and Service Facilities of Company $A$ as an Example
}

\author{
Jiangdong Bao ${ }^{1}$, Chaoju $\mathrm{Hu}^{1}$, Biyu $\mathrm{Liu}^{2,}{ }^{*}$, Shuiping Shi ${ }^{1}$ and Ping Dong ${ }^{1}$ \\ ${ }^{1}$ School of Economics and Management, Hanshan Normal Universtiy, Chaozhou 521041, China \\ baojiangdong@hstc.edu.cn (J.B.); huzj@hstc.edu.cn (Z.H.); 2580@hstc.edu.cn (S.S.); 20190008@hstc.edu.cn \\ (P.D.) \\ 2 School of Economics and Management, Fuzhou University, Fuzhou 350116, China \\ ${ }^{*}$ Correspondence: jasperseu@fzu.edu.cn; Tel.: +86-591-22866099
}

\begin{abstract}
With the focus of great concern of the sustainable development, its evaluation system has become an important operational strategy and practical values. For the purpose of obtaining the stronger indicators and the larger contribution ones, evaluation indicators screening is carried out using interval estimation model, which takes location of production and service facilities of company A as an example. And the weight value of each indicator is further explored, which can provide an direction of decision-making. The result shows that this screening method provides a more scientific evaluation method for enterprise location, decision-making basis for sustainable development of enterprises, and a solid foundation for the construction of the post-evaluation system. The present work implies that this screening method is affected, to different degrees, by the ability, knowledge reserve of the evaluators, which should be more systematic and standardized, and the concept of sustainable development should be strengthened.
\end{abstract}

Keywords: location; screening; interval estimation model;

\section{Introduction}

Evaluation means that through quantitative and non-quantitative measurement processes of the evaluation targets, the evaluators can reach a reliable and logical conclusion (Bao, 2018). However, when an evaluation system is set up for evaluation, there may exist redundant indicators under the condition of satisfying consistency test, which will affect the accuracy and scientificity of the evaluation results. There are also indicators that can't meet the consistency requirements, the reason is that the contribution of indicators has been overwhelmed by the error of the system, the indicators won't contribute substantially to the 
evaluation. Hence, the indicators need to be screened.

At present, the commonly used qualitative screening methods are theoretical analysis and expert consultation. According to Fan et al. (2002), Lin et al. (2012) and Li et al. (2017), the subjectivity of this method is too strong, and the analysis results are not accurate. Lu \& Jiang (2007), Liu (2005), and Mu et al. (2015) think the common methods of quantitative analysis include statistical analysis and Liu et al. (2004) and Lu \& Zhang (2008) give the grey relational analysis, but these two methods require a large amount of sample data and have some limitations. Based on these points, this article applies the interval estimation analysis method based on qualitative and quantitative Analytic Hierarchy Process (AHP) to eliminate redundant indicators and indicators that contribute little, to screen the location of production and service facilities for further research, and establishes a reliable indicator system foundation for the later evaluation.

\section{Description of Interval Estimation Model}

AHP method is a combination of qualitative and quantitative decision analysis, it has been applied to program optimization, comprehensive evaluation, feasibility judgment and so on in many fields (Bao et al., 2016, Bao et al., 2017(94), and Bao et al., 2017(133)). The basic method of AHP based on interval estimation is that only the indicators contributing to decision objectives can be used as criteria for measuring alternatives (Gao et al., 2005, Zhong \& Fu, 2012, Liu et al., 2012, Mao et al., 2007 and Wang, 2013). Because of the difference of knowledge, ability and information among the evaluators, there may be some errors in the scoring results (Sam et al., 1996). This is, if the importance of an indicator is small enough, or the contribution of that indicator has been obscured by systematic errors, it can't contribute substantially to system evaluation and should be eliminated (Bao, 2018, and Azadeh \& Zadeh, 2016). And the model steps are built as follows:

Step1. To build the judgment matrix. To compare the relative importance between the established standard layer and the target layer with 1 9 scale method proposed by Professor Thomas (Thomas, 2005). And to build the judgment matrix at each level as $A_{n}=\left(a_{i j}\right)_{n \times n}$.

Step2. To conduct the consistency test according to relative consistency indicator formula, where $C R=\frac{C I}{R I}, \lambda_{\max }=1 / n \sum_{i=1}^{n}(A W) / \omega_{i}, \lambda_{\max }$ is the maximum eigenvalue of judgment matrix, $n$ is the order of a judgment matrix, $R I$ is the mean random consistency indicator whose values are shown in Table 1. 
Table 1 RI Set Value

\begin{tabular}{cccccccccc}
\hline $\mathrm{n}$ & 1 & 2 & 3 & 4 & 5 & 6 & 7 & 8 & 9 \\
\hline $\mathrm{RI}$ & 0 & 0 & 0.58 & 0.9 & 1.12 & 1.24 & 1.32 & 1.41 & 1.45 \\
\hline
\end{tabular}

Step3. When $0 \leq C R \leq 0.1$, the judgment matrix has satisfactory consistency. The weight vector of the judgment matrix can be calculated as $W=\left[\omega_{1}, \omega_{2} \ldots \omega_{n}\right]^{T}$ with Yaahp software, then the appropriate indicators selection weight $\xi$ is selected to screen the indicators of this layer. (Normally, $\xi$ is set as 0.05 , if $W_{\mathrm{i}}>\zeta$ means there are no weak indicators.)

Step4. When $C R>0.1$, the judgment matrix can't meet the consistency requirement. The upper limit value $\omega_{i}^{U}$ and the lower limit value $\omega_{i}^{L}$ should be calculated according to interval estimation model, and the calculation should satisfy the following linear programming model (Takayama, 1998).

$\max (\min ) \omega_{i}$
s.t. $\left\{\begin{array}{l}\bar{A} W \leq 0 \\ W=\left[\omega_{1}, \omega_{2} \ldots \omega_{n}\right]>0 \\ \omega_{1}+\omega_{2}+\ldots \omega_{n}=1\end{array}\right.$

Step5. If the weight $\omega_{i}$ can satisfy $\omega_{i}^{u} \leq \Delta_{\max }$, where $\Delta_{\max } \leq \max _{1 \leq i \leq n}\left(\omega_{i}^{u}-\omega_{i}^{L}\right)$, then the contribution of this indicator has been masked by systematic error and should be eliminated.

\section{Construction of Evaluation Indicators for Location of Production and Service Facilities}

Location problems should be considered from a systematic point of view, because the whole production activity is a whole, it is impossible for enterprises to exist in isolation. Based on it, enterprises should consider not only suppliers but also customers, as well as product distribution (Chen \& Ma, 2016).

In general, the factors to be considered in location problems can be divided into four categories: economic factors, political factors, social factors and natural factors (Chen \& $\mathrm{Ma}$, 2016). Table 2 is designed for providing a framework for the implementation of location problems of production and service facilities. 
Table 2 Framework of Evaluation Indicators System for Location of Production and Service Facilities

\begin{tabular}{ll}
\hline First-grade Indicator & Second-grade Indicator \\
\hline Economic factors & Transport conditions and cost \\
& Energy accessibility and cost \\
& Site conditions and cost \\
\hline Political factors & Political situation \\
\hline Legal system \\
Tax revenue \\
\hline Living habits of residents \\
\hline Cultural and educational level \\
Religious belief \\
Living standard \\
\hline Climatic conditions \\
\hline
\end{tabular}

From a systematic point of view, location decision should minimize the cost of the whole production distribution chain. From the analysis of the actual situation, there are many constraints on the location of enterprises, such as the impact of the same type of enterprises in pre-location, etc. With the rapid development of production and economy, China has been paying more and more attention to the viewpoints of sustainable development such as environmental governance, consumption and emission, which play an important role in the location of production and service facilities. In some areas, even these sustainable development indicators are implemented by one-vote veto system (Chen \& Ma, 2016). 


\section{Evaluation Indicators Screening for Location of Production and Service Facilities--a Case}

\section{Study of Company A}

Company A is located in the south of China and its climate is between 15 and 37 degrees centigrade. It is a manufacturer and operator of chemicals, which is one of the largest chemical enterprises in the world with a scale of nearly 1,000 people. Considering the low cost of labor, raw materials and the saving of transportation costs, the company plans to build a new production and processing plant in B city, so the location becomes the first issue.

\subsection{Establishment of Preliminary Evaluation Indicator System for Location}

Considering its location framework and all the specific conditions that the enterprise will face, five senior evaluators, including one enterprise internal auditor, one enterprise external auditor, one enterprise senior manager and two members of trade associations in B City, adopted brainstorming method to evaluate the location factors. The results of the evaluation indicator system are shown in Table 3.

Table 3 Preliminary Evaluation Indicator System for Location of Production and Service Facilities

\begin{tabular}{ll}
\hline First-grade Indicator & Second-grade Indicator \\
\hline & $U_{11}$ Close to the market \\
& $U_{12}$ Close to the port \\
$U_{1}$ Economic factors & $U_{13}$ Easy to transport raw materials \\
& $U_{14}$ Rental fee \\
& $U_{15}$ Local economic level \\
& $U_{21}$ Local government stability \\
& $U_{22}$ Cooperation with local governments \\
& $U_{23}$ Perfect legal system of local government \\
$U_{2}$ Political factors & $U_{24}$ Reasonable tax burden of the local government \\
$U_{3}$ Social factors & $U_{25}$ Local government's attitudes towards chemical enterprises \\
\hline & $U_{31}$ Living habits of residents \\
& $U_{32}$ Cultural and educational level \\
\hline &
\end{tabular}




\begin{tabular}{l}
\hline U34 Living standard \\
$U_{35}$ Labor resources \\
\hline$U_{41}$ Adequate infrastructure nearby \\
$U_{42}$ Water resources situation \\
$U_{43}$ Moderate climatic conditions \\
$U_{44}$ Convenient treatment of pollutants \\
$U$
\end{tabular}

4.2 The indicator weight and consistency test of $W_{U_{1}-U_{4}}$

5 selected evaluators were invited to judge the importance of the indicators with AHP method. According to step 2, $\omega_{i}, A \omega_{i}$ and $\frac{A \omega_{i}}{\omega_{i}}$ of first-grade indicators can be calculated as shown follows.

Table 4 Calculation Results of First-grade Indicators

\begin{tabular}{cccccccccc}
\hline & $U_{1}$ & $U_{2}$ & $U_{3}$ & $U_{4}$ & $W_{i}$ & $A W_{i}$ & $A W_{i} / W_{i}$ & $C I=(\lambda-n) /(n-1)$ & $C R=C I / R I$ \\
\hline$U_{1}$ & 1 & 3 & 5 & 4 & 0.536 & 2.213 & 4.129 & & \\
$U_{2}$ & $1 / 3$ & 1 & 3 & 3 & 0.253 & 1.064 & 4.197 & & 0.071 \\
$U_{3}$ & $1 / 5$ & $1 / 3$ & 1 & $1 / 3$ & 0.074 & 0.311 & 4.188 & & \\
$U_{4}$ & $1 / 4$ & $1 / 3$ & 3 & 1 & 0.136 & 0.578 & 4.242 & & \\
\hline
\end{tabular}

From Table 4, it can be concluded that $W_{U_{1}-U_{4}}=[0.536,0.253,0.074,0.136], C R=0.071<0.1$, the result has passed the consistency test. Let indicator selection weight $\xi=0.05$, $\omega_{U_{1}-U_{4}}>0.05$, so, no weak indicators can be eliminated. 
4.3 The indicator weight and consistency test of $W_{U_{11}-U_{15}}$

In the same way, as shown in Table 5, $W_{U_{11}-U_{15}}=[0.323,0.323,0.208,0.104,0.043]$, $C R=0.091<0.1$, the result has passed the consistency test, but $\omega_{U_{15}}<0.05$, the result indicates it is a weak indicator which should be eliminated.

Table 5 Calculation Results of Wu11-u15

\begin{tabular}{ccccccccccc}
\hline & $U_{11}$ & $U_{12}$ & $U_{13}$ & $U_{14}$ & $U_{15}$ & $W_{i}$ & $A W_{i}$ & $A W_{i} / W_{i}$ & $\mathrm{CI}=(\lambda-\mathrm{n}) /(\mathrm{n}-1)$ & $\mathrm{CR}=\mathrm{CI} / \mathrm{RI}$ \\
\hline$U_{11}$ & 1 & 3 & 2 & 4 & 8 & 0.323 & 2.464 & 7.637 & & \\
$U_{12}$ & $1 / 3$ & 1 & 3 & 3 & 8 & 0.323 & 1.708 & 5.292 & & \\
$U_{13}$ & $1 / 2$ & $1 / 3$ & 1 & 2 & 8 & 0.208 & 1.027 & 4.937 & 0.111 & 0.091 \\
$U_{14}$ & $1 / 4$ & $1 / 3$ & $1 / 2$ & 1 & 2 & 0.104 & 0.482 & 4.632 & & \\
$U_{15}$ & $1 / 8$ & $1 / 8$ & $1 / 8$ & $1 / 2$ & 1 & 0.043 & 0.201 & 4.713 & & \\
\hline
\end{tabular}

4.4 The indicator weight and consistency test of $W_{U_{21}-U_{25}}, W_{U_{21}-U_{25}}$, and $W_{U_{21}-U_{25}}$

Using the same method, the weights, $C R$, weak indicators, and substantive contributions of $U_{21-25}, U_{31-35}$ and $U_{41-45}$ can be calculated as shown in Table 6.

Table 6 Calculation Results of Wu21-U45 and CR

\begin{tabular}{ccccc}
\hline & $\mathrm{W}_{\mathrm{i}}$ & $\mathrm{CR}$ & Weak Indicator & Substantive Contribution \\
\hline$U_{21}-U_{25}$ & $0.045,0.213,0.304,0.203,0.235$ & 0.076 & $U_{21}$ & $/$ \\
$U_{31}-U_{35}$ & $0.124,1.265,0.037,0.353,0.221$ & 0.064 & $U_{33}$ & $/$ \\
$U_{41}-U_{45}$ & $0.320,0.289,0.202,0.107,0.071$ & 0.139 & $/$ & no \\
\hline
\end{tabular}

\subsection{The calculation of interval estimation model}

Concluded from Table 6, $W_{U 21}=0.045<0.05$ and $W_{U 33}=0.037<0.05$ indicate that they are weak indicators, and should be eliminated. $C R_{441-U 45}=0.139>0.1$ indicates that the result hasn't passed the consistency test, interval estimation model should be adopted to calculate the 
upper and lower limit values of each indicator with LINGO 11.0 software. The results are shown in Table 7.

Table 7 Upper and Lower Limit Values and Weight Values

\begin{tabular}{lccccc}
\hline & $U_{41}$ & $U_{42}$ & $U_{43}$ & $U_{44}$ & $U_{45}$ \\
\hline Upper Limit Value & 0.180 & 0.129 & 0.049 & 0.116 & 0.139 \\
Lower Limit Value & 0.066 & 0.109 & 0.039 & 0.109 & 0.118 \\
$\Delta_{i}$ & 0.114 & 0.020 & 0.010 & 0.005 & 0.021 \\
$w_{i}$ & 0.320 & 0.289 & 0.202 & 0.107 & 0.071 \\
\hline
\end{tabular}

It can be concluded from Table 7 that only $\omega_{43}{ }^{U}<\Delta_{\max }$, that is, $0.049<0.114$, the contribution of the $U_{43}$ has been covered by systematic error, and it will not make substantive contribution to the system evaluation, and should be eliminated.

\subsection{Evaluation indicator system after screening and the result}

The eliminated indicators from Table 4 to Table 7 include $U_{15}$ (Local economic level), $U_{21}$ (Local government stability), $U_{33}$ (Religious belief), and $U_{43}$ (Moderate climatic conditions), and the remaining ones still need screening using the same method. The consistency test of $U_{11}-U_{45}$ has well satisfied the format $C R<0.1$, all the weight values of the indicators are greater than 0.05 , and the results imply that the final indicator system is effective, which is shown in Table 8.

Table 8 Evaluation indicator system with weight value after screening for Location of Production and Service Facilities

\begin{tabular}{ll}
\hline First-grade Indicator & Second-grade Indicator \\
\hline & $U_{11}$ Close to the market 0.323 \\
& $U_{12}$ Close to the port 0.323 \\
$U_{1}$ Economic factors 0.536 & $U_{13}$ Easy to transport raw materials 0.208 \\
\cline { 2 - 3 } & $U_{14}$ Rental fee 0.146 \\
\hline & $U_{22}$ Cooperation with local governments 0.213 \\
$U_{2}$ Political factors 0.253 & $U_{23}$ Perfect legal system of local government 0.346 \\
& $U_{24}$ Reasonable tax burden of the local government 0.208
\end{tabular}




\begin{tabular}{ll}
\hline & $U_{25}$ Local government's attitudes towards chemical enterprises 0.233 \\
\hline & $U_{31}$ Living habits of residents 0.251 \\
& $U_{32}$ Cultural and educational level 0.215 \\
$U_{3}$ Social factors 0.074 & $U_{34}$ Living standard 0.208 \\
& $U_{35}$ Labor resources 0.326 \\
\hline & $U_{41}$ Adequate infrastructure nearby 0.323 \\
& $U_{42}$ Water resources situation 0.301 \\
& $U_{44}$ Convenient treatment of pollutants 0.208 \\
& $U_{45}$ Emission Compliance 0.168 \\
\hline
\end{tabular}

In addition, in order to verify the accuracy of the results, two members of trade associations in B City were asked why $U_{15}, U_{21}, U_{33}$, and $U_{43}$ were screened. The reason is that the correlation degree between the screened indicators and the location is not high. In other words, they are not the key indicators for the location. From this perspective, this indicator screening method is scientific and feasible.

\section{Suggestion and Conclusion}

This study provides a more scientific method for enterprise location by eliminating weak indicators and indicators with little contribution, and the establishment of indicator weight also provides a decision direction for enterprise internal management. Importantly, this screening method improves the accuracy of the evaluation system, lays a good foundation for the later evaluation system, and is a methodological trend.

But inevitably this method is still a subjective evaluation, the results will be affected by the ability, knowledge reserve of the evaluators. Different evaluators may have different results for the same indicator evaluation. At the same time, from the evaluation results analysis, the weight value of economic factors is 3.94 times than that of natural factors. And, the weights of $U_{44}$ (Convenient discharge of pollutants) and $U_{45}$ (Emission compliance) are also the lowest under the first-level indicator of natural factors. From the perspective of sustainable development, this behavior of enterprises will affect the balanced development of economy, society and environment.

Faced with this dilemma, how to reduce the effect of the subjective factors of the evaluators and how to improve the attention of enterprise policymakers to sustainable development are both challenges.

For future work, this screening method should be more systematic and standardized, 
and at any time, for any enterprise, the concept of sustainable development is indispensable.

Acknowledgments: All authors thank the statistical personnel of the case study area for their cooperation in the study and leaders of the enterprise for the guidance. Hanshan Normal Universtiy funded the work reported in this paper. Special thanks to Biyu Liu for his proof reading.

Author Contributions: All authors contributed to design, method, and analysis reported in the paper. Zhaoju $\mathrm{Hu}$ conducted the fieldwork and collected and processed the data reported in the paper. BiyuLiu and Jiangdong Bao conducted the analysis and led the writing of the manuscript. Shuiping Shi and Ping Dong developed and prepared all tables and figures. All authors commented on the manuscript, providing insights used in the analysis and discussion.

Conflicts of Interest: The authors declare no conflict of interest.

\section{Rererences}

1. Azadeh, A.; Zadeh, S.A. An integrated fuzzy analytic hierarchy process and fuzzy multiple-criteria decision-making simulation approach for maintenance policy selection. Simulation. 2016, 1, 3-18.

2. Bao. J.D. Application of Statistical Methods on Occupational Health and Safety Management in the Mining Industry in Ezhou City, China. Luleå University of Technology Press. 2018.

3. Bao. J.D., Johansson.J., and Zhang. J.D. Comprehensive Evaluation on Employee Satisfaction of Mine Occupational Health and Safety Management System based on Improved AHP and 2-tuple Linguistic Information. Sustainability. 2017, 9(1), 133.

4. Bao. J.D., Johansson.J., and Zhang. J.D. Occupational Disease Assessment of Mine Industry Occupational Health and Safety Management System based on FMEA and Improved AHP Model. Sustainability. 2017, 9(1), 94.

5. Bao. J.D., Zhang. J.D., Li. F., Liu. C.Y., Shi. S.P. Social benefits of the mine occupational health and safety management systems of mines in China and Sweden based on a fuzzy analytic hierarchy process: A comparative study. Journal of Intelligent $\mathcal{E}$ Fuzzy Systems. 2016,31(6), 3113-3120.

6. Chen. R.Q., Ma. S.H. Production and Operation Management (Fourth Edition). Higher Education Press. 2016

7. Fan. B.N., Shan.S.T., Lu.C.S. Research on screening methods of evaluation index of urban technological innovation capability. Scientific Research. 2002, 20(6), 663-668.

8. Gao.J., Sun.L.Y., Li.M.Y. Interval estimation: a method of AHP indicator screening. System Engineering Theory and Practice. 2005,25(10),73-77.

9. Li. X., Tian.X.H., Du.W.H. Screening of drought resistance indexes of forage type triticale seedlings. Pratacultural Science. 2017,34(03),539-546.

10. Lin.L.M., Zhang.J.C. Liu.J.X., Long.P.Y., Tang.X. Shale gas exploration, target layer, optimization. Earth Science Frontiers. 2012,19(03), 259-263.

11. Liu.R.H., Yu.B., Jin.Z. Index selection of subway construction safety risk evaluation based on interval estimation. Forecast. 2012,31(02),62-66.

12. Liu.S.F., Dang.Y.G., Fang.Z.G. Grey system theory and its application. Science Press. 2004.

13. Lu.J.L.,Zhang.Z.G. Study on Markov residual correction model of mid long term power load rolling prediction based on grey relational index selection in BP neural network. East China Electric Power. 2008,9,15-18. 
14. Lu.N., Jiang.L.N. Study on index selection of real estate market prosperity in Xi'an. Journal of Chang'an University. 2007,9(3),57-60.

15. Liu.X. Research on evaluation indicator system of enterprise comprehensive ability based on circular economy. Nanjing University of Technology. 2005.

16. Mao.H.B., Zhang.F.M., Zou.W.G. A method of combination weighting for multiple attribute decision making based on interval estimation. System Engineering Theory and Practice. 2007,(06),86-92.

17. Mu.Y.Z., Lu.Z.X., Qiao.Y., Wang.Y., Huang.H., Zhou.Q.Y., Han.J.H. Comprehensive evaluation index system of power grid safety and benefit based on multi operator analytic hierarchy process fuzzy evaluation. Power Grid Technology. 2015,39(01),23-28.

18. Sam Skog.P.O., Bjorkman.J. Herbst.J. The implementation of process control of LKAB company in Kiruna - ore pellet plant. Foreign Metal Mines. 1996,3,37-43.

19. Takayama. I. Problem in AHP and ANP. Communications of the Operations. Research Society of Japan.1998,43,100-104.

20. Thomas, L.S. Making and validating complex decisions with the AHP/ANP. J. Syst. Sci. Syst. Eng. 2005, 14,1-36.

21. Wang.J., Tang.P.C., He.J.P. Selection of factors influencing fuel tax pricing in China based on AHP and interval estimation. Journal of Wuhan University of Technology (Traffic Science and Engineering). 2013,37(02),326-329.

22. Zhong.X.W., Fu.H.Y. Comprehensive evaluation method based on interval estimation and its application. Practice and Understanding of Mathematics. 2012,42(01),74-79. 